\title{
A Criminalização e a Marginalização dos Movimentos Sociais no Brasil Caso do Coletivo Feminista Pagu
}

\begin{abstract}
Thiago Henrique Costa Silva
Doutorando do Programa de Pós-Graduação em Agronegócio pela Universidade Federal de Goiás (UFG). Mestre em Direito Agrário pela Universidade Federal de Goiás (UFG). Especialista em Direito Público pela Uni-Anhanguera-Goiás. Especialista em Direito Pena e Processo Penal pela Universidade Municipal de São Caetano do Sul. Perito criminal da Superintendência de Polícia Técnico-Científica do Estado de Goiás. Professor de Direito Constitucional e pesquisador do Centro Universitário Alves Faria (Unialfa) e do Centro Universitário Alfredo Nasser (Unifan). thiagocostasilva.jur@gmail.com
\end{abstract}

\section{Maria Clara Capel de Ataídes}

Mestre e bacharel em Direito pela Universidade Federal de Goiás (UFG). Integrante da Rede de Pesquisa em Performances Culturais - Fapeg. Advogada. mariaclaracapel@gmail.com

Este trabalho tem como objetivo debater o fato de que, em um Estado Democrático de Direito, os movimentos sociais constituem instrumentos de resistência e reivindicação, quando enfrentam pautas que a sociedade civil ou outras entidades não teriam meios ou vontade política de abordar. Suas ações se constituem, a partir de seu diálogo com o Estado, em uma forma de ativismo público, e por isso legítima dentro do ordenamento jurídico vigente. O que pode ser depreendido da realidade brasileira, entretanto, é uma criminalização dessas formas de manifestação, de maneira a silenciar e tornar impossível a formulação desses ideais, que, na maioria dos casos, almejam mudanças e avanços políticos e jurídicos. Por fim, de forma a demonstrar a atuação do Estado em relação aos movimentos sociais, por meio do método dedutivo, em abordagem qualitativa, analisa-se o caso do coletivo feminista Pagu e a tentativa de imputar a prática de vilipêndio a objetos religiosos, no Estado de Goiás, um exemplo da pauta antidemocrática, conservadora e hegemônica em que a sociedade e as formas políticas brasileira estão envolvidas. Palavras-chave: Criminalização. Controle social penal. Movimento social. Ativismo público.

\section{THE CRIMINALIZATION AND THE MARGINALIZATION OF SOCIAL MOVEMENTS IN BRAZIL: THE CASE OF THE PAGU FEMINIST COLLECTIVE}

\section{ABSTRACT}

This paper aims to discuss that, in a democratic State of law, social movements are instruments of resistance and demand, when they face guidelines that civil society or other entities would not have the means or political will to address. Their actions constitute, through their dialogue with the State, in a form of public activism, and therefore legitimate within the current legal order. However, what can be deduced from the Brazilian reality is a criminalization of these forms of manifestation, in order to silence and render impossible the formulation of these ideals, which, in most cases, seek changes and political and legal advances. Finally, in order to demonstrate the State's action in relation to social movements, by means of the deductive method, in qualitative approach, the case of the feminist collective Pagu is analyzed and the attempt to impute the practice of vilification to religious objects in the Goiás state, an example of the antidemocratic, conservative pattern and hegemony in which Brazilian society and political forms are involved.

Keywords: Criminalization. Criminal social control. Social movement. Public activism.

\section{SUMÁRIO}

1 Introdução. 2 Movimentos sociais, democracia e ativismo público. 3 A criminalização dos movimentos sociais: faces de um Estado autoritário. 3.1 O Movimento social como inimigo do Estado. 3.2 O Estado da não democracia e do não direito: caminhos para um Estado de exceção. 3.30 controle social como ferramenta criminológica hegemônica. 40 silêncio dos contrários: a tentativa de calar os movimentos sociais. 4.10 feminismo do Coletivo Pagu e o conservadorismo da Faculdade de Direito da Universidade Federal de Goiás. 5 Considerações finais. 6 Referências. 


\section{INTRODUÇÃO}

O objetivo deste artigo é debater acerca dos instrumentos estatais que permitem a compreensão dos movimentos sociais como inimigos do Estado, fundamento do discurso da necessidade de um controle social cada vez mais rígido. A criminalização dos movimentos sociais e de suas práticas passa a ser regra em um Estado de exceção, como forma de manutenção de uma ordem vigente e hegemônica. Por outro lado, pretende-se evidenciar como os movimentos sociais conseguiram evoluir e se enquadrar em contextos históricos distintos, por meio de estratégias de reivindicação de direitos, tornando-se essenciais ao exercício democrático em qualquer sociedade.

A partir dos referenciais teóricos-metodológicos da criminologia crítica, o trabalho observará o método dedutivo, ancorado metodologicamente por uma pesquisa bibliográfica e documental, que permitirão uma análise questionadora da realidade a partir de um estudo de caso: o do coletivo feminista Pagu.

Primeiramente, buscar-se-á delinear a importância dos movimentos sociais para a construção de um Estado democrático de direito. Os movimentos sociais, como configurações que se inserem na estrutura jurídica-política vigente, atuam a partir de um ativismo público, ou seja, dão voz à determinada parte da sociedade por meio de ações legítimas, coordenadas e com finalidades específicas, expressando uma forma de resistência e reivindicação de direitos que não costumam ser efetivados ou, até mesmo, que dependem de uma mudança de postura legislativa e estatal.

A atuação dos movimentos sociais será analisada conforme uma perspectiva diferente da que os caracteriza como antidemocráticos, badernas coletivas ou ilegais. Ao contrário, com a perspectiva do ativismo público, esses movimentos poderão ser visualizados como um grupo de sujeitos que tornam as lutas visíveis, provocam mudanças e fazem girar a roda democrática.

Em sequência, a criminalização dos movimentos sociais e os aparatos estatais que justificam essa conduta serão abordados. Serão apresentados os conceitos de direito penal do inimigo e de estado de exceção, com o objetivo de correlacionar essas teorias ao que ocorre na prática brasileira. Ao tentar coibir a prática dos movimentos sociais e de seus atos, criminalizando suas condutas, o poder público retira direitos fundamentais dos indivíduos, como o de se manifestar livremente e exercer sua cidadania, e os trata como verdadeiros inimigos, que devem ser combatidos e expurgados do convívio social. Em decorrência desse discurso, o movimento antidemocrático, ocasionado por essa penalização de sujeitos, suprime direitos e garantias fundamentais, tornando regra um estado de exceção no qual tudo é possível para combater o "mal" que assola a sociedade.

Em seguida, salienta-se o controle social, sobretudo penal, exercido pelo Estado, desde a formulação das leis e a escolha dos temas objetos de criminalização até as decisões judiciais que acabam por sufocar os movimentos sociais. A escolha ideológica estatal, amparada pelo poder de convencimento da mídia, constrói uma imagem distorcida dessas forças sociais, afastando-as de sua realidade e de seus objetivos essenciais. Assim, as bandeiras e ideais dessas resistências são escondidas pela "fama" de desordeiros, criminosos e perturbadores da ordem social.

Por último, a pretensão será a de demonstrar como os conceitos levantados anteriormente são relevantes para compreender a realidade brasileira, que a cada dia caminha para o silenciamento de mais movimentos sociais, objetivando torná-los incapazes de mobilizar a 


\section{Humanos e \\ Democracia}

sociedade e provocar mudanças políticas e jurídicas. O poder, que emana do povo, está nos votos, no plebiscito e nos referendos, e também na discussão diária das políticas públicas, nas manifestações e movimentos sociais, na contraposição de ideias, na fiscalização e na possibilidade de denúncia dos erros por parte de todos os integrantes da sociedade.

Nessa perspectiva, será analisado o caso do movimento feminista do Estado de Goiás (o coletivo Pagu e a tentativa de criminalização de seus atos em meados de 2016). O coletivo Pagu, movimento estudantil que levanta bandeiras feministas, teve suas representantes investigadas pela polícia civil a partir de denúncia do diretor da Faculdade de Direito da Universidade Federal de Goiás. A situação demonstrou a dificuldade de parte da academia, a qual deveria se constituir em um espaço aberto às mais diferentes discussões e pontos de vistas, para enxergar o movimento social como espaço de discussão da realidade (im)posta.

Sendo assim, o artigo pretende colocar em evidência a necessidade latente de que as instituições e legislações brasileiras contemplem instrumentos de participação coletiva, em que os movimentos sociais se inserem como uma forma plural e conectada à realidade de discussão, resolução e gestão de conflitos.

\section{MOVIMENTOS SOCIAIS, DEMOCRACIA E ATIVISMO PÚBLICO}

Os movimentos sociais representam estruturas jurídicas constituídas pela própria sociedade e suas ações. Quando um grupo de sujeitos é afastado de direitos essenciais, que integram aquilo que possui de mais importante, sua dignidade e sua liberdade em se constituir com plenitude na sociedade como sujeitos de direitos, ocorrem agrupamentos. Os mesmos se dão a partir de afinidades, que formam coletivos de ideias e reivindicações, que, em sua resistência, buscam a formação de novos direitos.

Flórez Flórez (2009) indica que esses movimentos constituem atores privilegiados para provocar difíceis transformações, que não seriam tão factíveis a partir de outras organizações, como partidos políticos e instituições de ações sociais. São eles que enfrentam temas como: o esgotamento do sistema econômico, as questões ambientais, a reforma agrária, os direitos das minorias, dentre tantos outros.

É bem verdade que os movimentos sociais, no sentido de questionar modelos postos e oferecer alternativas, existem há bastante tempo. Por volta das décadas de 60 e 70, encontraram maiores resistências em virtude da guerra ideológica entre socialismo e capitalismo, e foram, muitas vezes, caracterizados, por isso, como subversivos, revolucionários e perigosos. Em meados dos anos 80 , contudo, o Estado democrático de direito cedia espaço às diferentes manifestações de pensamento, reconhecendo os movimentos sociais como legítimos e fundamentais à democracia.

Ao surgir do próprio Estado e de suas fragilidades, os movimentos sociais complementam a democracia, retirando do poder público a exclusividade de criar uma ordem jurídica. Por meio de um pluralismo de modos de enfrentar a realidade, eles corroboram para a construção de uma justiça democrática e participativa, que consegue dar voz aos mais distintos interesses que compõem dada sociedade (WOLKMER, 2015). 
O direito não é formado a partir da academia, mas sim das margens e dos conflitos sociais. As constituições surgem desse rompante de ideias de determinados grupos ou, quando democrática, de variados grupos. Dessa forma, "toda a sociedade política tem sua própria constituição, corporalizando suas tradições, costumes e práticas que ordenam a tramitação do poder" (WOLKMER, 2011).

Nota-se que não se fala aqui em subversão de uma ordem democrática ou social, mas que os movimentos sociais configuram um exercício de liberdade e de participação social. Orientam-se, assim, de forma organizada e inserida dentro de uma estrutura política, com ações visíveis, periódicas e não violentas, por meio de estratégias de enfrentamento contra-hegemônico. É o que Carter (2010) procura demonstrar, conceituando esse tipo de atividade como formas de ativismos públicos, que seriam:

As ações promovidas pelo ativismo popular voltam-se a: (1) atrair a atenção pública; (2) influenciar as políticas do Estado por meio de pressão, do lobby e das negociações; e (3) configurar as ideias, os valores e as ações da sociedade em geral. Normalmente, as mobilizações desse tipo empregam uma série de repertórios modernos de ação coletiva, como demonstrações, marchas, petições, reuniões de discussão, greves de fome, acampamentos de protesto e campanhas eleitorais, além de atos de desobediência civil, como piquetes, bloqueios de estradas e ocupações organizadas de terra e de prédios públicos. Diferentemente de outras abordagens ao conflito social, a orientação não violenta do ativismo público faz com que ele seja compatível com a sociedade civil e proporcione um instrumento democrático legítimo para fomentar a mudança social (p. 203).

O autor elenca dois requisitos básicos para que o ativismo ocorra: as oportunidades políticas, caracterizadas pelas possibilidades oferecidas pelas organizações de poder, que podem favorecer ou impossibilitar o exercício dos movimentos sociais; e os recursos mobilizadores, consubstanciados por uma rede de recursos humanos, materiais e imateriais. Essa formatação, que deve ser garantida por qualquer Estado democrático, possibilita que os movimentos sociais se unam a grupos da sociedade civil e a grupos políticos, no intuito de pressionar e exigir uma nova postura do Estado.

Ainda, Carter (2010) salienta a importância do equilíbrio desses fatores, pois o objetivo central de um ativismo público é possibilitar a participação política ativa de diferentes segmentos da sociedade. Dessa forma, se os recursos mobilizadores são baixos e as oportunidades políticas elevadas, ter-se-á uma "confrontação desordeira", uma espécie de "revolta dispersada". Já se o inverso ocorre, e os recursos mobilizadores são altos, em detrimento de uma baixa oportunidade política, pode surgir uma "luta agressiva e armada". Por fim, se ambos os fatores são insuficientes, dar-se-á lugar aos "pedidos suplicantes" e resistências cotidianas e enfraquecidas.

Basta observar que a Constituição da República Federativa do Brasil, datada de 1988, conceitua o Estado brasileiro como democrático de direito, para concluir que o Brasil optou por estabelecer um complexo de normas e princípios para garantir o exercício democrático. Para isso, o constituinte estabeleceu o voto secreto, direto e universal, a possibilidade de referendo e plebiscito, o pluralismo partidário e, até mesmo, a possibilidade de impeachment. 


\section{Humanos e}

Democracia

Esses elementos, em conjunto com a separação de poderes, o sistema de freios e contrapesos e as diversas formas de controle, a exemplo dos exercidos pelo Ministério Público e pelos Tribunais de Contas, devem permitir um Estado livre e participativo.

Ora, quando a CF/88, em seu artigo 5o, prevê os direitos e garantias fundamentais e destaca a liberdade entre eles, pode ser feito um paralelo com o texto de Carter (2010), e não restam dúvidas quanto à possibilidade de exercício de um ativismo público por parte dos movimentos sociais, que nada mais seriam que um instrumento para o exercício da democracia.

Bobbio (1987) afirmou, contudo, que, mesmo nas sociedades consideradas mais avançadas, apesar de assegurados o voto universal e a existência de partidos políticos e da mobilização política, a democracia não conseguiu oferecer itens como a participação efetiva e um controle dos governados em relação aos governantes. Por isso, de um lado estaria a "apatia política" ou ausência de participação e, de outro, a "participação distorcida", baseada na manipulação das massas por quem detém o poder ideológico.

De modo a manter essa falsa democracia participativa, o Estado acaba por rechaçar os movimentos sociais, a começar pelos mais atuantes e que geram uma expectativa de mudança maior, posto que questionam elementos consolidados, a exemplo dos movimentos que lutam pela reforma agrária ou por uma sociedade que consolide a equidade entre as muIheres e os homens. Os governos, sob o argumento de manter uma pretensa ordem vigente, utilizam-se da criminalização e da judicialização dos atos e sufocam o verdadeiro ativismo público.

A partir dessas formulações, é necessário investigar a forma com a qual o Estado brasileiro se comporta em relação aos movimentos sociais, quais instrumentos são utilizados para estabelecer essa relação e quais as consequências dessas escolhas políticas.

\section{A CRIMINALIZAÇÃO DOS MOVIMENTOS SOCIAIS: FACES DE UM ESTADO AUTORITÁRIO}

Poulantzas (2000), em sua obra "O Estado, o poder e o socialismo", publicada originalmente em 1978, descreve uma forma de relação poder-saber como modo de dominação hegemônica por parte do Estado, que impõe à sociedade, sobretudo às massas populares que ocupam a base da pirâmide produtiva, um modelo controlável e repetível.

... essa relação poder-saber se traduz por técnicas particulares de exercício do poder, por dispositivos precisos, inscritos na trama do Estado, de distanciamento permanente das massas populares dos centros de decisão: por uma série de rituais, de formas de discurso, de modos estruturais de tematização, de formulação e tratamento dos problemas pelos aparelhos de Estado de maneira tal (monopolização do saber) que as massas populares (nesse sentido trabalho manual) ficam de fato à parte disso (POULANTZAS, 2000, p. 58).

O grande pensador, assim, afirma a reprodução da dominação de classes, que, com o auxílio estatal, consegue manter um consenso ideológico das classes políticas dominantes. Isso ocorre por meio dos aparelhos do Estado (políticos ou midiáticos) ou por intermédio da violência, até mesmo física, às classes dominadas. Estas, por sua vez, organizam-se em torno de uma desconfiança em relação aos aparelhos ideológicos (POULANTZAS, 2000). 
Nesse contexto, o Estado apropria-se do discurso de transformação social, resistência e lutas por direitos dos movimentos sociais, e o transforma em uma lógica de baderna, formação de organizações criminosas e perturbação da ordem pública. Ao agir dessa forma, imputa a esses sujeitos uma violência que não é somente física, mas simbólica, e constrói um arcabouço de normas e instituições capazes de manter uma pretensa ordem.

De modo a tornar crível o exercício dessa violência, o discurso de lei e ordem, baseado na proteção da propriedade e dos bons costumes, é institucionalizado. Isso ocorre com o aval de parte da sociedade, que acredita estar sendo protegida, quando, na verdade, é tolhida em seu direito genuíno de reivindicar e cobrar do poder público aquilo que lhe é de direito (POULANTZAS, 1977).

Essa violência legitimada é a verdadeira face do autoritarismo estatal ante a democracia no Brasil. Nesse sentido, "o autoritarismo, quer dizer, o novo discurso da lei e da ordem, da segurança dos cidadãos, das necessárias restrições aos abusos das liberdades democráticas [é reeditado com ares de democrático]" (POULANTZAS, 1983, p. 78).

Ao longo deste tópico, portanto, o anseio será o de demonstrar teorias que têm como objeto a relação entre os movimentos sociais e os aparelhos estatais, bem como a violência que ocorre nesse espaço. Será realizada, então, uma leitura, a partir dessas teorias, da realidade brasileira.

\subsection{O Movimento social como inimigo do Estado}

Desenvolvido por Gunther Jakobs, o direito penal do inimigo é baseado na teoria jurídico-penal da prevenção geral positiva como legitimadora da pena criminal, que consistiria na estabilização das expectativas normativas explicitada por Luhman (SANTOS, 2008).

Segundo Jakobs, o Estado pode proceder de duas formas com aqueles que fogem às normas: pode tratá-los como pessoas que cometeram um erro - continua sendo um cidadão - ou como indivíduos que devem ser impedidos de destruir o ordenamento jurídico, mediante coação - esse seria designado como inimigo (JAKOBS; MELIÁ, 2007).

A pena para o cidadão seria uma reação a determinado fato, de modo a afirmar a validade da norma e reprimir o fato passado, ou seja, o crime que a contradiz. Por outro lado, a pena para o inimigo seria uma medida de força, que configuraria uma custódia de segurança, uma espécie de obstáculo que se antecipa ao fato futuro do crime, prevenindo sua contrariedade (SANTOS, 2008).

Com base nessa divisão, os cidadãos seriam autores de crimes normais, que não contrariariam as expectativas normativas de determinada sociedade. Continuariam, portanto, possuidores de direito. Os inimigos, enquanto isso, seriam autores de crimes de alta traição, configurados por uma insubordinação jurídica intensa e capazes de produzir um estado de guerra. Por isso, perderiam a qualidade de pessoas de direito (SANTOS, 2008).

É possível depreender, portanto, que o autor propõe a separação da sociedade em dois grupos para a aplicação do direito penal, de modo que, para os inimigos, direitos e garantias inerentes a quaisquer pessoas não seriam necessariamente aplicáveis. 


\section{Humanos e}

Democracia

Além de um óbvio desrespeito aos direitos humanos e do mínimo de dignidade que se deve delegar às pessoas, esse processo de escolha também é questionável no sentido de que, afinal, quem seriam os inimigos? Estupradores, homicidas, traficantes, ímprobos administrativos, terroristas? Com toda certeza essa delimitação guardaria enorme subjetivismo e forçaria escolhas ideológicas daqueles que fossem operar o sistema criminal.

Basta compreender os ideais de um Estado democrático de Direito e o complexo sistema de garantias processuais e penais para saber que seria impossível, do ponto de vista formal, adotar o modelo proposto por Jakobs. Contrariando essa premissa, em relação aos movimentos sociais:

o que se observa, portanto é que a violência policial desmedida não é a única arma usada pelo Estado no enfrentamento das manifestações populares, qualificadas como um "inimigo" pelos poderes instituídos, a partir dos rótulos de "baderna" e "vandalismo". Promove-se a demonização dos movimentos populares e, a pretexto de combatê-los, o Estado tem se valido de medidas fortemente autoritárias, totalmente impróprias em um Estado Democrático de Direito (BARROS; ANDRADE, 2014, p. 3).

Dessa maneira, o que vem se concretizando é uma verdadeira configuração dos integrantes dos movimentos sociais como inimigos do Estado, o que legitima os mais amplos abusos, como a ampliação dos fatos típicos para abarcar suas condutas, ou mesmo a atuação policial, seja ela civil ou militar, de forma diferenciada e direcionada à criminalização desses sujeitos. As palavras da Via Campesina, em uma cartilha produzida durante o Fórum Social Mundial em 2010, denominada "a ofensiva da direita para a criminalização dos movimentos sociais", trazem que:

o objetivo da criminalização é criar as condições legais e, se possível, legítimas perante a sociedade para: a) impedir que a classe trabalhadora tenha conquistas econômicas e políticas; b) restringir, diminuir ou dificultar o acesso às políticas públicas; c) isolar e desmoralizar os movimentos sociais junto à sociedade; d) e, por fim, criar as condições legais para a repressão física aos movimentos sociais (VIA CAMPESINA BRASIL, 2010, p. 6).

Essa tentativa de criminalização ficará ainda mais clara nos próximos tópicos, que demonstram como o Estado tende a retirar direitos dos integrantes de diversos movimentos sociais, tornando suas lutas invisíveis ou ilegítimas perante a sociedade.

\subsection{O Estado da não democracia e do não direito: caminhos para um Estado de exceção}

Agamben conceitua o Estado de exceção como verdadeiro, oposto ao Estado Democrático de Direito, de modo que esse tipo de conformação deveria estar condicionado às situações de urgência ou emergência nacional em que, de forma temporária, os direitos e garantias fundamentais poderiam ser suspensos, contudo o "espaço juridicamente vazio do estado de exceção [...] irrompeu de seus confins espaço-temporais e, esparramando-se para fora deles, tende agora por toda parte a coincidir com o ordenamento normal, no qual tudo se torna assim novamente possível" (AGAMBEN, 2004, p. 44).

Dessa forma, o Estado de exceção poderia ser visualizado como uma tática de suspensão de direitos de pessoas ou grupos que representem algum tipo de perigo ao Estado, possibilitando, assim, a eliminação de adversários do sistema (BARROS; ANDRADE, 2014). 
Sob o pretexto de proteção da ordem vigente e da paz social, os Estados vêm, a cada dia, adotando a exceção como regra, abolindo gradualmente os direitos e liberdades individuais. O crescente autoritarismo estatal é a forma de exercício político e de administração que confronta diariamente qualquer chance real de democracia e de participação, integração de toda a sociedade nas escolhas e efetivação de políticas públicas diversas, haja vista que qualquer pensamento que não o hegemônico, ou de quem não detém o poder, passa a ser marginalizado e expurgado do restante da sociedade.

O governo brasileiro vem adotando, cada vez mais, uma política de exceção em relação aos movimentos sociais, como bem-assevera Souza (2015, p. 185):

Invariavelmente, a resposta estatal aos legítimos levantes populares fazia recorrer ao uso do aparato policial como forma de contenção da "besta feroz" e ao Direito Penal como estratégia de criminalizar as rebeldias em ebulição. Longe de dialogar ou atender às demandas da sociedade civil, o Estado entoa como mantra a resposta única, qual seja, a criminalização dos movimentos sociais.

Um exemplo dessa intenção estatal é a aprovação às pressas do projeto de Lei 499/2013, que culminou na chamada Lei Antiterrorismo. Em meio às pressões populares, a referida lei visava a enquadrar várias manifestações populares no rol de crimes, demonstrando claramente o seu ideal antidemocrático, uma verdadeira forma de usar os mecanismos estatais contra as garantias dos cidadãos.

A aprovação do projeto foi alvo de intensa crítica por parte de alguns juristas que defenderam que os atos de violência porventura praticados por manifestantes poderiam ser perfeitamente enquadrados em outros dispositivos já existentes na lei penal, como é o caso do crime de dano, homicídio ou sequestro. A lei, portanto colocaria em risco o estado de direito, abrindo espaço para a criminalização política (BARROS; ANDRADE, 2014, p. 20).

Ao suprimir direitos, criminalizar condutas e subverter os argumentos de manifestações democráticas legítimas, o Estado caminha para o autoritarismo antidemocrático, que legitima a violência física e jurídica contra aqueles que se posicionam, de alguma forma, questionando a ordem vigente.

\subsection{O controle social como ferramenta criminológica hegemônica}

Após descrever o direito penal do inimigo de Jakobs e o estado de exceção de Agamben, o objetivo desse tópico será o de demonstrar as estratégias do Estado brasileiro para criminalizar os movimentos sociais, seus integrantes e suas ações.

É fato que uma das funções do Estado é exercer o controle social das inúmeras atividades inerentes aos vários grupos da sociedade. A forma como esse controle ocorre, entretanto, deve ser meticulosamente pensada. Quando se fala de movimentos sociais, a falta de compreensão do poder público em relação ao ativismo público e a sua importância para a democracia, leva o Estado a distorcer as medidas de adequação de seus mecanismos.

Segundo Shecaira (2011, p. 60), o controle social pode ser delimitado como:

o conjunto de mecanismos e sanções sociais que pretendem submeter o indivíduo aos modelos e normas comunitários. Para alcançar tais meras as organizações sociais lançam mão de dois sistemas articulados entre si. De um lado tem-se o controle social informal, 


\section{Humanos e \\ Democracia}

que passa pela instância da sociedade civil: família, escola, profissão, opinião pública, grupos de pressão, clube de serviço, etc. Outra instância é a do controle social formal, identificada com a atuação do aparelho político do Estado. São controles realizados por intermédio da Polícia, da Justiça, do Exército, do Ministério Público, da Administração Penitenciária e de todos os consectários de tais agências, como controle legal, penal, etc.

O controle social pode ocorrer de maneira formal, realizado pelo Estado e por suas instituições, ou informal, praticado por diversos grupos geradores de qualquer influência no ser humano, e que não integram o Estado, tais como igrejas, escolas e famílias. Quanto ao modo de ação, pode ser preventivo, antes da prática de determinada conduta, ou repressivo, depois do exercício dessa conduta (CARDOSO, 2012).

Sob o ponto de vista informal, é fácil depreender que todos os movimentos sociais, de forma direta ou não, sofrem interferências nos âmbitos familiares, educacionais e religiosos, seja por imposição de suas crenças e dogmas ou por simples interações com determinadas características. É no controle formal, no entanto, que reside a estratégia estatal de interferência nos mecanismos de atuação dos movimentos sociais.

Isso ocorre desde o processo legislativo e a formulação das leis penais, que devem garantir os direitos fundamentais, até a atividade combativa das polícias judiciárias e militares, que possuem o papel de retirar do convívio normal da sociedade aqueles que não correspondam às expectativas. No controle formal também atua o Ministério Público, que, como promotor da ação penal, transpõe a causa para o Judiciário, e este, por fim, deve promover a justiça (CARDOSO, 2012).

É possível observar que a crítica não está no controle social realizado, mas, sim, na forma com que é refletida uma escolha política, de caráter hegemônico e de demonstração de poder, direcionada para uma finalidade: a criminalização dos movimentos sociais. Esse discurso criminalizante, por sua vez, deslegitima as reivindicações populares, em que expressões, como vândalos e desordeiros, são instrumentos para a captura política dos movimentos pelo sistema penal (SOUZA, 2015).

\section{O SILÊNCIO DOS CONTRÁRIOS:}

\section{A Tentativa de Calar os Movimentos Sociais}

Os movimentos sociais vêm sofrendo uma tentativa de silenciamento por parte dos poderes públicos, que tentam, de todas as formas, conter o ímpeto questionador trazido pelas manifestações. Como forma de luta e resistência que são, críticos de um modelo hegemônico e que, por vezes, não corresponde aos seus anseios, os integrantes dos movimentos se expressam de forma legítima, organizada e ativa, o que incomoda os que se beneficiam da situação vigente.

A transformação que esses grupos buscam e seus exercícios de democracia são deturpados pelo Estado, de todas as formas, com a criminalização, ou tentativa, de suas condutas, e a taxação de seus atos como atividades de baderneiros que não sabem conviver em sociedade, o que culmina na judicialização de suas ações. 
A não assimilação desses movimentos sociais como uma maneira de participação direta na sociedade e como uma forma de ativismo público, é geradora de um Estado autoritário, o qual não consegue administrar um ambiente democrático que contém ideias diversas daquelas que são dominantes. Por isso, nesse capítulo foi escolhido o caso do coletivo Pagu para demonstrar como o poder público brasileiro tem se pautado em relação aos diversos movimentos sociais e suas práticas.

\subsection{O feminismo do coletivo Pagu e o conservadorismo da \\ Faculdade de Direito da Universidade Federal de Goiás}

No dia 17 de dezembro de 2015, na cidade de Goiânia, Goiás, especificamente na Faculdade de Direito da Universidade Federal de Goiás, alguns cartazes foram afixados com frases de luta contra a violência de gênero. Um deles continha a seguinte mensagem: "Tire seus rosários dos meus ovários".

Por conseguinte, duas professoras, um técnico-administrativo e um estudante solicitaram providências por parte do diretor da faculdade, que abriu um procedimento administrativo e encaminhou o caso para a Polícia Civil, por suspeitar que a manifestação configurava vilipêndio público a objeto de culto religioso (EMPÓRIO DO DIREITO, 2016).

O documento, elaborado pelas professoras, servidor e estudante e encaminhado pelo diretor, continha as seguintes informações:

Noticiamos que nesta data fomos surpreendidos com a presença de cartazes apócrifos espalhados pelas paredes da Faculdade de Direito da UFG, contendo os mesmos, mensagens de supostos militantes dos movimentos LGBTs e feministas. Em tais mensagens, constava, além daquelas referentes à ideologia de gênero e sexual, outras ofensivas aos professores e aos membros da comunidade acadêmica que professam sua religião cristã.

Notadamente um dos cartazes está impresso com a seguinte frase: TIREM SEUS ROSÁRIOS DOS MEUS OVÁRIOS.

(...)

O Código Penal prevê no Art. 208: "Escarnecer de alguém publicamente, por motivo de crença ou função religiosa; impedir ou perturbar cerimônia ou prática de culto religioso; vilipendiar publicamente ato ou objeto de culto religioso:

Pena - detenção, de um mês a um ano, ou multa".

Ora, o Santo Rosário é objeto de culto católico e deve, portanto, ser tratado com respeito por católicos e não católicos, como merecem respeito o livro da Bíblia e o Alcorão, por exemplo (EMPÓRIO DO DIREITO, 2016). 


\section{Humanos e \\ Democracia}

Diante do que considerou uma impostura administrativa, mais grave quando se tratava de uma faculdade de direito pública, o professor João da Cruz Gonçalves Neto comunicou o fato à Reitoria ,pedindo providências, tornadas Processo Administrativo Disciplinar contra a figura do então senhor diretor. ${ }^{1}$

Tal procedimento administrativo foi arquivado, segundo o relatório a seguir, por não ter configurado infração disciplinar:

A liberdade de expressão é uma prerrogativa constitucional e a expressão de opiniões divergentes deveria servir para a construção de uma sociedade capaz de abrigar as diferenças. É claro, também, que se deve observar que o anonimato é vedado. Desse modo, consideramos que não houve ato de intolerância religiosa, mas que os autores dos cartazes deveriam assiná-los, assumindo as suas proposições reivindicatórias com clareza (EMPÓRIO DO DIREITO, 2016).

Em relação ao procedimento policial, o delegado de polícia Washington da Conceição passou a ouvir os noticiantes (que esclareceram não terem visto quem haveria colocado os cartazes, mas que suscitaram a suspeita sobre o coletivo Pagu) e a solicitar documentos e imagens de câmeras de segurança.

Após quase nove meses de investigação, no dia 16/9/2016 a autoridade policial da 9a Delegacia da Polícia Civil de Goiânia, no intuito de apurar o fato, intimou quatro alunas integrantes do coletivo feminista Pagu para prestar esclarecimentos, individual e sucessivamente, do dia 19 ao 21.

Sendo assim, no dia 19 de setembro, com base na demora da investigação, no não lavramento do Termo Circunstanciado de Ocorrência (TCO), na atipicidade do fato, no abuso e desvio de poder do uso da persecução penal apenas para reprimir o debate de determinados temas na faculdade de direito, a advogada, Bartira Miranda dos Santos, também professora da Universidade Federal de Goiás (UFG), impetrou um Habeas Corpus (HC) com a finalidade de trancar a investigação.

\footnotetext{
Único professor a se posicionar abertamente em defesa dos possíveis alunos e alunas (não sabidos ainda hoje) que afixaram os cartazes até o trancamento da investigação criminal. Pode-se ler em sua solicitação à Reitoria: "Assim, muito claramente, a tentativa de assumir o lugar de vítima de discriminação religiosa denuncia a intenção de intimidar, ameaçar, conter, limitar, reprimir a iniciativa de jovens inteligentes que esperavam da universidade muito mais que o medíocre disciplinamento moral. Não bastasse as reprimendas individualizadas que se faz individualmente, na sala da diretoria, às alunas que pertencem ao Coletivo Pagu (jovens ligadas ao meu projeto de extensão de estudo acadêmico do feminismo), a direção convocou a polícia para denunciar, como eventuais criminosos, nossos alunos. Por ter afixado os cartazes acima descritos! Por crime contra a liberdade religiosa, um crime de ódio, inafiançável, imprescritível, que atenta contra a dignidade da pessoa! Exatamente aqueles jovens idealistas que querem lutar por um mundo simplesmente mais respeitoso e melhor. 0 desconsolo, a indignação, o repúdio a tão deplorável ação nos faz pensar: em qual universidade no mundo nós precisamos convocar a POLíCIA para mediar um problema pedagógico, para executar uma tarefa crítica, dialógica, educacional, que é só nossa? Essa é a maior declaração de incompetência profissional já assumida publicamente de que temos notícia em nossa faculdade. Como nós, educadores, podemos explicar aos pais e à sociedade que estamos tentando levar nossos jovens universitários aos tribunais antes mesmo de seus professores terem compreendido os princípios mais elementares de nossa Constituição e dos fins institucionais de nossa universidade? Esta universidade quer formar que tipo de profissional e cidadão? Diante de um panorama político que se fecha em nosso país, com supressão crescente de direitos, é como uma ratificadora de um regime de exceção que a universidade quer ser apresentada aos jornais e às gerações futuras?"
} 
É importante mencionar que o diretor da Faculdade de Direito já havia, sob os mesmos argumentos, notificado a polícia federal. O Ministério Público Federal (procurador Marco Túlio de Oliveira e Silva), entretanto, alegando ausência de tipicidade da conduta, manifestou-se pelo arquivamento do inquérito, argumento acolhido de pronto pela Justiça Federal (juiz Eduardo Pereira da Silva). Em sua petição, assevera o membro do parquet federal:

Ao que parece a frase "tirem seus rosários dos meus ovários. Religião e direito não se confundem" representa insurgência contra a postura católica, também adotada por diversos outros seguimentos religiosos, de oposição a movimentos que pretendem a descriminalização do aborto. Não parece que o autor da frase "tirem seus rosários dos meus ovários" tenha pretendido dar a ela sentido literal. A linguagem é figurada. Os "rosários", na interpretação deste órgão ministerial, indicam referência não ao objeto litúrgico, mas ao seguimento religioso que o utiliza. Tampouco, os "ovários" indicam referência ao órgão do aparelho reprodutor feminino, mas ao pretendido direito de autodeterminação reprodutiva por meio da prática do aborto. Tal interpretação é reforçada pela frase seguinte: "Religião e direito não se confundem" (EMPÓRIO DO DIREITO, 2016).

Assim, no curso do julgamento do Habeas Corpus, em sede da justiça estadual, o juiz de direito, Denival Francisco da Silva, julgando a liminar, concedeu a ordem. Isso ocorreu com o fim de determinar à autoridade policial que cessasse, em definitivo, a investigação criminal, com base na ausência de tipicidade criminal e em respeito à coisa julgada, conforme excerto da decisão:

Mais do que o constrangimento imposto às pacientes para que compareceram à Delegacia de Polícia para prestarem declarações, sob a ameaça inclusive de responderem por desobediência em caso de não atendimento, pesa a evidente atipicidade do fato que já foi inclusive reconhecida noutra persecução penal que foi conduzida na Justiça Federal. Neste caso há arbitrariedade e abuso por conta da ausência de fato típico, claramente perceptível, e em face ao desrespeito à coisa julgada (TJGO, 2016).

Desse modo, o fatídico caso envolvendo o coletivo Pagu deu-se por encerrado, mas deixou as marcas de perseguição do movimento, com a tentativa de se utilizar do controle social penal e da judicialização do conflito para tolher a liberdade de expressão assegurada constitucionalmente.

O movimento feminista reverbera os questionamentos das mulheres em relação a sua condição e às diversas imposições que existem tão somente pela questão de gênero. Cada vez mais organizadas, as mulheres lutam por sua liberdade, por igualdade, pelo fim dos preconceitos, pela dignidade e por tantas outras bandeiras, constituindo verdadeira forma de resistência à sociedade machista e patriarcal que ganha corpo em inúmeras culturas.

Uma forma de ativismo público, de provocação dos poderes públicos, os movimentos feministas, ao longo da história, originaram mudanças estruturais, jurídicas, legislativas e culturais.

Mas a chamada primeira onda do feminismo aconteceu a partir das últimas décadas do século XIX, quando as mulheres, primeiro na Inglaterra, organizaram-se para lutar por seus direitos, sendo que o primeiro deles que se popularizou foi o direito ao voto. As sufragetes, como ficaram conhecidas, promoveram grandes manifestações em Londres, foram presas várias vezes, fizeram greves de fome. Em 1913, na famosa corrida de cavalo em Derby, a feminista Emily Davison atirou-se à frente do cavalo do Rei, morrendo. O direito ao voto foi conquistado no Reino Unido em 1918. No Brasil, a primeira onda do feminismo também se manifestou mais publicamente por meio da luta pelo voto. As 


\title{
Humanos e \\ Democracia
}

\begin{abstract}
sufragetes brasileiras foram lideradas por Bertha Lutz, bióloga, cientista de importância, que estudou no exterior e voltou para o Brasil na década de 1910, iniciando a luta pelo voto. Foi uma das fundadoras da Federação Brasileira pelo Progresso Feminino, organização que fez campanha pública pelo voto, tendo inclusive levado, em 1927, um abaixo-assinado ao Senado, pedindo a aprovação do Projeto de Lei, de autoria do Senador Juvenal Larmartine, que dava o direito de voto às mulheres. Este direito foi conquistado em 1932, quando foi promulgado o Novo Código Eleitoral brasileiro (PINTO, 2010, p. 15-16).
\end{abstract}

Desse modo, o movimento feminista passa a encarar dois principais objetivos: a) empoderar as mulheres, tornando-as capazes de uma mobilização e de uma busca por direitos, em uma conquista cada vez maior de uma situação de liberdade e igualdade; e b) possibilitar o aumento de representatividade das mulheres junto a sociedade, seja ocupando lugares de destaque no âmbito político, seja um destaque na sociedade civil organizada, dentre outros (PINTO, 2009).

Desde os seus primeiros passos, a razão de ser do movimento feminista foi "empoderar" as mulheres (mesmo que o conceito tenha sido incorporado como vocabulário muito posteriormente). Se, por uma parte, o movimento logrou conquistas indiscutíveis que atingiram as próprias estruturas de poder no mundo ocidental, por outra, tem sido muito tímido em interpelar mulheres para agirem no mundo público e, principalmente, político (PINTO, 2010, p. 22).

Ora, nesse sentido, é fundamental que as mulheres representem o que de fato pertence a elas, o que é realizado por diversos grupos feministas. É certo, assim, que todos esses grupos almejam ocupar um lugar de destaque e de possibilidade de participação e inserção social, de modo a fazer as suas vozes serem ouvidas.

No intuito de se manifestarem e darem voz às suas angustias e opiniões, um conjunto de algumas estudantes da Universidade Federal de Goiás, com a intenção de discutir e agir em questões inerentes ao machismo, racismo, preconceitos e feminismo, fundaram, em 2014, o Coletivo Pagu. Este coletivo, ainda em ação, tem como um de seus objetivos principais promover atividades acadêmicas envolvendo temas ligados aos direitos das mulheres por meio de palestras, debates públicos, grupos de estudos de obras feministas e apresentações artísticas. Diante da completa lacuna de estudos feministas no projeto pedagógico do curso de direito da UFG, o Coletivo pretendeu registrar suas atividades acadêmicas como um projeto de extensão universitária, sob amparo de um professor, não tendo sido jamais aprovado nos 18 meses em que tramitou no Conselho Diretor da faculdade, até ser retirado de pauta pelo próprio Coletivo, consternado com os inúmeros artifícios protelatórios utilizados para não aprovar formalmente a proposta.

Nota-se que grupos feministas são frequentemente taxados como "baderneiros", e suas integrantes denominadas "feminazis". A união de mulheres é constantemente classificada de maneira pejorativa por uma sociedade de visão patriarcal. O Coletivo, contudo, é exemplo de como essa perspectiva é distorcida e embasada em argumentos vazios, uma vez que o grupo se constitui, em sua maioria, de estudantes, as quais buscam formar uma consciência coletiva que expresse direitos assegurados constitucionalmente, como liberdade e igualdade.

Sua organização ocorre dentro de um contexto institucional e segue premissas de um estado democrático de direito. O movimento existe, portanto, como forma de ativismo público, dentro de uma instituição de Ensino Superior que, inclusive, deveria estimular o pensamento crítico de seus estudantes. A criminalização, no entanto, ganhou destaque em sobreposição ao debate de ideias. 
Contrária a tal dimensão dada aos movimentos sociais, a desembargadora do Tribunal de Justiça do Estado de São Paulo, Kenarik Boujikian, assevera:

Minha grande preocupação é que existe um movimento de criminalização das lutas que se reflete de forma muito clara em relação aos movimentos de mulheres. Começam a pipocar casos dessa natureza em que o direito à manifestação - e principalmente o direito de manifestação das questões relativas aos direitos das mulheres - não é reconhecido (PRADO, 2016).

Sobre a tentativa de imputação de crime e vilipêndio público a objeto de culto religioso, vale dizer que o delito em questão não prescinde do dolo de desonrar um indivíduo em razão de sua religião (BITTENCOURT, 2009, p. 790), ou seja, não há que falar em vilipêndio se o propósito difere da ofensa direta. Além do mais, utilizar o objeto ou mencioná-lo de maneira lúdica, crítica, engraçada ou poética, exclui a tipicidade (NUCCl, 2009, p. 897).

É evidente que o ato, ainda que tivesse sido assinado pelo Coletivo Pagu, não passa de uma forma crítica e poética de tratar do tema do aborto e suas inferências religiosas, em especial da igreja católica, sobre o tema. O Brasil, conforme afirma a constituição de 1988, é um Estado Laico, portanto é possível que diversas pessoas pratiquem as religiões que queiram, ou ainda não pratiquem. É livre, também, o direito de se expressar e o de discordar de qualquer opinião, inclusive religiosa. Dessa forma, fica evidente que a notícia do crime, iniciada no âmbito federal e, após não lograr êxito, no âmbito estadual, buscou criminalizar o movimento social a qualquer custo.

Diferente do controle oferecido a casos que ocorrem frequentemente em nossa sociedade (como a prisão de membros do MST sob a acusação de formação de quadrilha, desobediência e esbulho possessório²), o controle social penal, exercido no caso do coletivo Pagu, não foi completado com a repressão do Judiciário, posto que a judicialização do caso foi, ao contrário, a solução do impasse. Configurar os movimentos feministas como inimigos do Estado, todavia, é uma tentativa de deturpar a democracia, silenciando um grupo que já, costumeiramente, não tem voz em um sistema repleto de falhas no que se refere ao tratamento das mulheres e seus direitos.

\section{CONSIDERAÇÕES FINAIS}

Com base no caso tratado e nas teorias levantadas, é possível mencionar que a criminalização dos movimentos sociais vem sendo uma estratégia de certos grupos, e até mesmo do Estado, para silenciar ideias e frear atos contrários à dominação hegemônica em curso.

\footnotetext{
CONSTITUCIONAL. PROCESSUAL PENAL. PRISÃO EM FLAGRANTE. LÍDERES DO MST. LIBERDADE PROVISÓRIA. - A prisão processual, medida extrema que implica sacrifício à liberdade individual, deve ser concebida com cautela em face do princípio constitucional da presunção de inocência, somente cabível quando presentes razões objetivas, indicativas de atos concretos, susceptíveis de causar prejuízo à ordem pública, à instrução criminal e à aplicação da lei penal (CPP, art. 315; CF, art. 93, IX). - A manutenção de líderes do Movimento dos Trabalhadores Rurais Sem Terra - MST - sob custódia processual, sob a acusação de formação de quadrilha, desobediência e esbulho possessório afronta o preceito inscrito no artigo 5o, LXVI, da Constituição. - Habeas-Corpus concedido (STJ. HC 9.896/PR, rel. ministro VICENTE LEAL, SEXTA TURMA, julgado em 21/10/1999, DJ 29/11/1999, p. 206).
} 


\section{Humanos e \\ Democracia}

Por outro lado, os movimentos sociais configuram verdadeiras formas de exercício da democracia. Ao agirem em respeito ao ordenamento jurídico vigente, mas tornando claras suas contradições, reverberando ideias que perpassam pontos de vistas diferentes, tocando em assuntos que não são abordados, senão por eles, os movimentos são formas de ativismo público, que devem ser incentivados por qualquer Estado democrático.

O ativismo público é a forma mais direta e participativa de dar voz aos diversos grupos que compõem uma sociedade. É a maneira mais objetiva e efetiva de integrar o poder público, as leis e seus agentes do pluralismo existente em qualquer Estado nação. As possibilidades de debates, entretanto, vêm sofrendo com o imenso controle social imputado aos movimentos que promovem e aprofundam a democracia.

Como forma de legitimação da criminalização como estratégia, as instituições brasileiras buscam tornar possível o tratamento diferenciado dos movimentos sociais, atribuindo-lhes a pecha de inimigos do Estado, retirando algumas de suas garantias e direitos como medida de exceção.

Com o auxílio midiático, que divulga os movimentos sociais das formas mais pejorativas possíveis, o Estado consegue imputar, inclusive com apoio popular, títulos de baderneiros, criminosos e vândalos aos diferentes movimentos. Com a certeza de que todos os integrantes e seus atos não representam nada de bom ao país e à democracia, ao contrário, são perigosos à ordem social vigente, parte da população legitima a criminalização desses grupos e o Estado os marginaliza como pode.

Não menos importante, o controle social, com ênfase para o penal, é a metodologia empregada no intento de retirar os movimentos sociais e a sua influência do âmbito da sociedade. Começando pela elaboração das leis, passando pela atividade policial e do Ministério Público, ou ainda por diversas instituições que compõem a administração pública, culminando na repreensão por parte do Poder Judiciário, as atividades, atos e a simples formação dos coletivos são levados à justiça, que teria o papel final do processo criminalizador: o de aplicar a lei e punir os integrantes dos movimentos individual e coletivamente.

As considerações aqui tecidas ficam demonstradas na análise do caso exposto no terceiro tópico. O emblemático caso envolvendo o coletivo feminista Pagu, iniciado por provocações internas da academia jurídica, revela como os tipos penais são deturpados para enquadrar as ações dos movimentos e como a sua simples ação de se manifestar é motivo para judicialização e tentativa de punição.

Inviabilizar as críticas do coletivo Pagu, tornando-as um delito qualquer, é o caminho possível para a hegemonia do pensar ou uma ditadura da maioria, mas nunca para uma democracia. Desconhecer a importância do ativismo público para conformar o poder público às diferentes realidades que integram dada sociedade, desconfigura a necessidade de existir do próprio Estado, pois é na representação dessas diferentes visões que ele se funda e pode se afirmar como democrático de direito.

Em tempo, o principal objetivo deste artigo não é afirmar que todos os atos, somente por se originarem de movimentos sociais, devam ser inobservados pelo Estado; pelo contrário, o objetivo é ressaltar a importância de estabelecer um diálogo da sociedade com as estruturas estatais e promover verdadeiras mudanças sociais. É função dos governantes e 
políticos estabelecer uma agenda de integração dessas novas ideias, que sempre surgem de onde existem conflitos e divergências. Repensar modos de aproveitar o ativismo público e de estimular a participação da pluralidade de sujeitos que formam a sociedade, é tarefa árdua, mas que merece atenção dos pesquisadores e profissionais de diversas áreas do conhecimento, incluindo os vinculados ao direito.

\section{REFERÊNCIAS}

AGAMBEN, Giorgio. Estado de exceção: homo sacer II, 1. São Paulo: Boitempo, 2004.

BARROS, Anna Flávia Magalhães de Caux; ANDRADE, Janaina Diniz Ferreira de. Do inimigo ao estado de exceção: uma análise da tentativa de criminalização das manifestações populares no Brasil. In: CONPEDI; UNB; UCB; IDP; UDF (org.). Direitos fundamentais e democracia. Florianópolis: CONPEDI, 2014.

BITENCOURT, César Roberto. Código Penal Comentado. 5. ed. atual. São Paulo, SP: Editora Saraiva, 2009. BOBBIO, Norberto. Qual socialismo? Discussão de uma alternativa. 3. ed. Rio de Janeiro: Paz e Terra, 1987.

CARDOSO, Franciele Silva. A luta e a lida: estudo do controle social do MST nos acampamentos e assentamentos de reforma agrária. 2012. Tese (Doutorado) - Universidade de São Paulo, São Paulo, 2012.

CARTER, Miguel. Origem e consolidação do MST no Rio Grande do Sul. In: CARTER, Miguel (org.). Combatendo a desigualdade social: o MST e a Reforma Agrária no Brasil. São Paulo: Editora Unesp, 2010. p. 199-235.

EMPÓRIO DO DIREITO. Professora pede Habeas Corpus para estudantes da Faculdade de Direito acusadas de afixar cartazes feministas. set. 2016. Disponível em: http://emporiododireito.com.br/professora-pede-habeas-corpus-para-estudantes-da-faculdade-de-direito-acusadas-de-afixar-cartazes-feministas/. Acesso em: 15 nov. 2018. FLÓREZ FLÓREZ, Juliana. Los movimientos sociales y la crisis del desarrollismo: una aproximación teórica desde Latinoamérica. 1. ed. Buenos Aires: Consejo Latinoamericano de Ciencias Sociales - Clacso, 2009.

JAKOBS, Günther; MELIÁ, Manuel Cancio. Direito Penal do Inimigo. Noções críticas. Org. e trad. André Luís Callegari e Nereu José Giacomolli. 2. ed. Porto Alegre: Livraria do Advogado Ed., 2007. p. 9-50.

NUCCl, Guilherme de Souza. Código Penal Comentado. 9. ed. rev., atual. e ampliada. São Paulo: Editora Revista dos Tribunais, 2009.

PINTO, Céli Regina Jardim. Feminismo, história e poder. Curitiba: Revista de Sociologia e Política, v. 17, n. 36, p. 15-23, jun. 2010.

POULANTZAS, Nicos. As transformações atuais do Estado, a crise política e a crise do Estado. In: POULANTZAS, Nicos (org.). O Estado em crise. Rio de Janeiro, Edições Graal, 1977.

POULANTZAS, Nicos. O Estado, o poder e o socialismo. 4. ed. São Paulo: Ed. Paz e Terra, 2000.

POULANTZAS, Nicos. O Estado, os movimentos sociais, o partido. Espaços e Debates: Revista de Estudos Regionais e Urbanos, São Paulo, ano III, maio/ago. 1983.

PRADO, Débora. Tire seus rosários dos meus ovários: decisão da Justiça de Goiás reitera direito de manifestação feminista. 28 set. 2016. Disponível em: http://agenciapatriciagalvao.org.br/direitos-sexuais-e-reprodutivos/tire-seus-rosarios-dos-meus-ovarios-decisao-da-justica-de-goias-reitera-direito-de-manifestacao/. Acesso em: 20 out. 2018. SHECAIRA, Sérgio Salomão. Criminologia. 3. ed. São Paulo: Revistas dos Tribunais, 2011.

SOUZA, Taiguara Líbano Soares e. Estado Policial e Criminalização dos Movimentos Sociais. Notas sobre a inconstitucionalidade do Decreto № 44.302/13 do governo do Estado do Rio de Janeiro. Revista EMERJ, Rio de Janeiro, v. 18, n. 67 , p. 185-205, jan./fev. 2015.

STJ. Superior Tribunal de Justiça. Habeas Corpus 9.896/PR. Relator ministro Vicente Leal, sexta turma, julgado em 21de outubro de 1999, DJ 29/11/1999, p. 206.

TJGO. Tribunal de Justiça de Goiás. Decisão de Habeas Corpus. 24 set. 2016. Disponível em: http://agenciapatriciagalvao.org.br/wp-content/uploads/2016/09/DFS_HC_Trancamen to-Inquerito-Policial.pdf. Acesso em: 20 out. 2018.

VIA CAMPESINA BRASIL. A ofensiva da Direita para criminalizar os Movimentos Sociais no Brasil. São Paulo, 2010. WOLKMER, Antônio Carlos. Novos sujeitos sociais e a construção plural de direitos. In: TÁRREGA, Maria Cristina Vidotte Blanco; SCHWENDLER, Sônia Fátima (org.). Conflitos agrários, seus sujeitos, seus direitos. Goiânia: Ed. PUC Goiás, 2015. p. 285-290.

WOLKMER, Antônio Carlos. Pluralismo e crítica do constitucionalismo na América Latina. SIMPÓSIO DE DIREITO CONSTITUCIONAL DA ABDCONST, 9., 2011. Curitiba. Anais [...]. Curitiba, PR: ABDConst., 2011. 